thường do nguyên nhân tình trạng ứ đọng mủ trong hòm nhĩ căng làm tăng áp lực và làm thủng màng nhĩ thoát mủ ra ngoài. Bệnh nhi không có triệu chứng chảy mủ tai chiếm tỷ lệ $77,5 \%$, nhóm này hình ảnh nội soi màng nhĩ thấy sung huyết hoặc căng phồng ứ mủ. Những bệnh nhi khi nhập viện điêu trị với lỗ thủng màng nhĩ và có chảy mủ tai thường là những trường hợp đến viện muộn, trong tình trạng tự điều trị hoặc theo dõi ở nhà không đúng cách nên khi có dấu hiệu chảy mủ do có lỗ thủng màng nhĩ mới được đưa đi khám điều trị.

So sánh với nghiên cứu của Kay và cộng sự cùng Ah-Tye và cộng sự trên những bệnh nhi được đặt ống thông khí trong giai đoạn viêm tai giữa cấp có từ $26 \%$ đến $75 \%$ có dấu hiệu chảy mủ tai [8],[9]. Ở những bệnh nhi khi được nạo VA thì cũng làm giảm $10 \%$ phải đặt ống thông khí lại so với đặt ống thông khí đơn thuần. Do đó lựa chọn phương pháp điều trị phù hợp đúng giai đoạn tránh tình trạng chảy mủ tai, đau, sốt làm giảm chất lượng cuộc sống của bệnh nhi.

\section{KẾT LUÂN}

Đánh giá mối liên quan giữa triệu chứng lâm sàng với hình ảnh nội soi màng nhĩ trong viêm tai giữa cấp giúp xác định chính xác giai đoạn của bệnh viêm giữa cấp và đưa ra phác đồ điều trị phù hợp, kịp thời tránh bỏ sót bệnh và các biến chứng do viêm tai giữa cấp có thể gây ra.

\section{TÀI LIÊU THAM KHẢO}

1. Amina Danishyar, John V. Ashurst: Acute Otitis Media. StatPearls Publishing LLC. (2021)

2. Robert M Siegel, James P Bien: Acute otitis media in children: A continuing story. Pediatrics in Review; Vol.25 No.6; 25(6):187-93 (2004).

3. Helen Atkinson, Sebastian Wallis et al: Acute otitis media. Postgraduate Medicine; 127(4): 386390 (2015).

4. Shaikh, N. et al. Responsiveness and construct validity of a symptom scale for acute otitis media. Pediatr. Infect. Dis. J. 28, 9-12 (2009).

5. Rothman, R., Owens, T. \& Simel, D. L. Does this child have acute otitis media? JAMA 289, 1633-1640 (2003).

6. Niemela $M$, Uhari $M$ et al: Lack of specific symptomatology in children with acute otitis media. The padiatric infectious disease journal; 13(9):765-768 (1994).

7. Staphen Berman: Management of acute and chronic otitis media in pediatric practice. Current opinion in pediatrics; 7(5):513-22 (1995).

8. Kay, D. J., Nelson, M. \& Rosenfeld, R. M. Meta-analysis of tympanostomy tube sequelae. Otolaryngol. Head Neck Surg. 124, 374-380 (2001).

9. Ah-Tye, C., Paradise, J. L. \& Colborn, D. K. Otorrhea in young children after tympanostomytube placement for persistent middle-ear effusion: prevalence, incidence, and duration. Pediatrics $107,1251-1258$ (2001).

\title{
ĐÁNH GIÁ CHỨC NĂNG ĐAI TIÊN VÀ MỘT SỐ YẾU TỐ LIÊN QUAN SAU PHẪU THUẦT Nộ̂I SOI CẮT TRƯớC THẤP ĐIỀU TRI UNG THƯ TRỰC TRÀNG
}

\author{
Hồ Hữu An*, Triệu Triều Dương*, Diêm Đăng Bình*, \\ Nguyễn Văn Trưởng*, Lê Văn Quốc*, Vũ Ngọc Sơn*, \\ Phạm Thị Huế*, Ngô Thị To*, Trần Thị Hà*, \\ Lê Đăng Trung*, Nguyễn Thị Tri*
}

\section{TÓM TẮT}

Đă̆t vấn đề: Rối loạn chức năng đại tiện sau phẫu thuật là vấn đề thách thức ảnh hưởng nhiều đến chất lượng sống của bệnh nhân sau phẫu thuật. Mục đích nghiên cứu nhắm đánh giá chức năng đại tiện của bệnh nhân sau phẫu thuật nội soi cắt trực tràng trước thấp. Phương pháp nghiên cứu: Nghiên cứu mô tả tiến cứu trên 82 bệnh nhân ung thư trực tràng được

*Bệnh viên Trung ương Quân đội 108

Chịu trách nhiệm chính: Hồ Hữu An

Email: bs.hohuuan83@gmail.com

Ngày nhận bài: 14.9.2021

Ngày phản biên khoa hoc: 29.10.2021

Ngày duyệt bài: 17.11 .2021 phẫu thuât nôi soi cắt trước thấp từ tháng 7/2018 đến 7/2020. Đánh giá theo thang điểm Hồi chứng cắt trước thấp (LARS) và Wexner tai thời điểm 3 tháng, 6 tháng và 12 tháng. Kết quả: tuổi trung bình 62,3 tuổi, có $65,9 \%$ nam và $34,1 \%$ nữ. Chức năng đại tiên thay đổi rõ rệt sau 1 năm: điểm trung bình LARS sau 3 tháng, 6 tháng và 12 tháng lần lướt là 17,$6 ; 14,0$ và 10,6 . Trong đó $56,1 \%$ bệnh nhân không có LARS sau 3 tháng tăng lên $75,6 \%$ sau 12 tháng. Tỷ lê bệnh nhân LARS nặng sau 3 tháng $26,8 \%$ giảm còn $14,6 \%$ sau 12 tháng. Điểm Wexner: sau 3 tháng là 5,9 giảm còn 3,4 sau 12 tháng. Tỷ lệ bệnh nhân đại tiện bình thường sau 3 tháng $28,0 \%$ tắng lên $46,3 \%$ sau 12 tháng. Sau 3 tháng có $11,0 \%$ bệnh nhân mất tự chủ hoàn toàn giảm cờn $7,3 \%$ sau 12 tháng. Các yểu tố: hóa xạ trị tiền phẫu $(p=0,017)$, vị trí khối u $(p=0,02)$ 
và phương pháp thực hiện miệng nối $(p=0,01)$, vị trí miệng nối $\left(p_{\tilde{N}}=0,000\right)$ có liên quan đến mức độ LARS nặng sau phẫu thuật. Kết luận: Rối loạn chức năng đại tiện ở nhóm bệnh nhân ung thư trực tràng được phẫu thuật nội soi cắt trước thấp là vấn đề thường gặp và kéo dài sau phẫu thuật, chức năng đại tiện sẽ được phưc hồi dân theo thời gian. Cân theo dởi, tư vấn và hỗ trợ giúp cho bệnh nhân để cải thiện chất lượng sống tổt hơn.

\section{SUMMARY \\ ASSESSMENT OF BOWEL MOVEMENT DYSFUNCTION AND RISK FACTORS FOLLOWING LAPAROSCOPIC LOW ANTERIOR RESECTION FOR RECTAL CANCER}

Introduction: Postoperative bowel movement dysfunction is a challenging problem that greatly affects the quality of life of patients after low anterior resection. The purpose of the study was to evaluate the bowel movement function of patients with rectal cancer who were undergone laparoscopic low anterior resection. Methods: Retrospective study of 82 rectal cancer patients who underwent laparoscopic low anterior resection from July 2018 to July 2020 at 108 Military Central Hospital, Hanoi, Vietnam. Results: mean age was 62.3 , there were $65.9 \%$ males and $34.1 \%$ females. The bowel movement function changed significantly after 1 year: the average score of LARS after 3 months, 6 months, and 1 year were $17.6 ; 14.0$ and 10.6 , respectively. In which, the rate of patients with major LARS after 3 months of $26.8 \%$ decreased to $14.6 \%$ after 1 year. Wexner score: after 3 months 5.9 decreased to 3.4 after 1 year. The rate of patients with normal bowel movements after 3 months $28.0 \%$ increased to $46.3 \%$ after 1 year. After 3 months, $11.0 \%$ of patients with complete faecal incontinence decreased to $7.3 \%$ after 1 year. Risk factors: preoperative chemoradiotherapy $(p=0.017)$, tumor location $(p=0.02)$ and method of anastomosis $(p=0.01)$, anastomosis location $(p=0.000)$ is associated with the major LARS after surgery. Conclusion: Bowel movement dysfunction in rectal cancer patients undergoing laparoscopic low anterior resection is a common and persistent problem after surgery. However, bowel function will gradually recover over time. Therefore, it is necessary to monitor and support patients to have a better quality of life.

\section{I. ĐẶT VẤN ĐỀ}

Ung thư trực tràng là bệnh lý ác tính khá phổ biến ở đường tiêu hóa. Theo GLOBOCAN 2018, có khoảng 704000 ca ung thư trực tràng mắc nới, và nó là nguyên nhân gây tự vong chiếm $3,2 \%$ tổng số ca tử vong do ung thư. Điều trị ung thư trực tràng đã có nhiều bước tiến trong những thập niên gần đây đó là đảm bảo tối ưu kết quả ung thư học và nâng cao chất lượng sống của bệnh nhân sau điều trị.

Với sự tiến bộ của điều trị bồ trợ (hóa xạ tiền phẫu), trang thiết bị cũng như những hiểu biết đầy đủ về mặt ung thư học đã giúp cho bệnh nhân ung thư trực tràng có thể bảo tồn được tối đa hậu môn. Tuy nhiên, có đến $80 \%$ bệnh nhân ung thư trực tràng sau phẫu thuât găp rối loạn về chức năng đại tiện như mức độ khẩn cấp khi đại tiện, đại tiện thường xuyên và mót rặn hay còn gọi là hội chứng cắt trực tràng trước thấp (LARS). Để đánh giá chức năng đại tiện sau phẫu thuật ung thư trực tràng thang điểm LARS được đưa ra với ưu điểm là dễ sử dụng và độ chính xác cao. Điểm số cho thấy mối tương quan tốt có độ nhạy $(72,54 \%)$ và độ đặc hiệu $(82,52 \%)$ cao cho LARS mức độ nặng [5]. Ngoài ra, thang điểm Wexner là một công cụ khác để đánh giá tự chủ của hậu môn [5]. Qua các nghiên cứu cho thấy tỷ lệ gặp hội chứng sau phẫu thuật cắt trực tràng khoảng 46,4-89,7\% [1],[3]. Chúng tôi thực hiện nghiên cứu này nhằm đánh giá chức năng đại tiện của bênh nhân ung thư trực tràng được phẫu thuật nội soi cắt trực tràng trước thấp dựa trên 2 thang điểm LARS và Wexner.

\section{II. ĐỐI TƯỢNG VÀ PHƯƠNG PHÁP NGHIÊN CỨU}

Nghiên cứu theo phương pháp mô tả tiến cứu trên bệnh nhân ung thư trực tràng được phẫu thuật nội soi cắt trực tràng trước thấp tại Bệnh viện TWQĐ 108 từ tháng 7 năm 2018 đến tháng 7 năm 2020.

Tiêu chuẩn lứa chọn: bệnh nhân ung thư trực tràng chưa có di căn xa được phẫu thuật nội soi cắt trước thấp. Loại trừ những bệnh nhân phẫu thuật theo phương pháp Hartmann, phẫu thuật cắt cụt trực tràng (Miles), bệnh nhân chết trong quá trình theo dôi, bệnh nhân có biến chứng miệng nối phải làm hậu môn nhân tạo, những bệnh nhân mất thông tị liên lạc...

Chẩn đoán giai đoạn trước mổ bằng cộng hưởng từ (CHT) tiểu khung (3.0 Tesla Philips Achieva MRI Scanner, Netherlands) và chụp cắt lớp vi tính ngực bunng (Somatom Definition As 64, Siemens Healthineers, Germany). Đối với bệnh nhân giai T3-4 và/hoặc $N(+)$ được hóa xạ trị tiền phẫu dài ngày $(50,4 G y$ chia thành 28 mũi trong 5 tuần, kèm theo uống Xeloda (Capecitabine) (F. Hoffmann-La Roche Ltd, Switzerland) 5 ngày/ tuần và trong 5 tuần).

Tất cả bênh nhân được phẫu nội soi cắt trực tràng trước thấp. Đối với ung thư trực tràng trển (u cách mép hậu môn $10-15 \mathrm{~cm}$ ) được phẫu thuật nội soi cắt bán phần mạc treo, đối với ung thư trực tràng giữa -dưới được phẫu thuật cắt toàn bộ mạc treo trực tràng (TME), cắt trực tràng gian cớ thắt (ISR). Miệng nối đai tràng-trực tràng được thực hiện bằng máy nối vòng (EEA ${ }^{\top M}$ 
Circular Stapler with Tri-Staple ${ }^{\mathrm{TM}}$ Technology, covidien) theo kiểu tận - tận, đâu xa trực tràng được cắt bằng stapler thẳng 3 hàng ghim (Endo GIA 45mm, Covidien). Miệng nối đại tràng - ống hậu môn được thực hiện bằng tay.

Tiêu chuẩn đánh giá chức năng đại tiện. Thang điểm LARS là một công cụ đánh giá bao gồm 5 mục: Đại tiện không tự chủ với hơi (0-7 điểm), đại tiện không tự chủ với phân lỏng (0-3 điểm), tần suất đại tiện (0-5 điểm), đại tiện nhiều lần trong 1 giờ (0-11 điểm) và mức độ khẩn cấp (0-16 điểm). Dựa vào số điểm được chia thành các mức độ: 0-20 (không có LARS), 21-29 (LARS nhẹ) và 30-42 (LARS nặng).

Thang điểm Wexner cũng bao gồm 5 mục như sau: đại tiện không tự chủ với phân rắn (0-4 điểm), đại tiện không tự chủ với phân lỏng (0-4 điểm), đại tiện không tự chủ với hơi (0-4 điểm), mang bỉm (0-4 điểm), thay đổi cuộc sông (0-4 điểm). Mức độ nghiêm trọng được chia thành: 0 điểm (bình thường), 1-8 điểm (đại tiện không kiểm soát mức độ nhẹ), 9-14 điểm (đại tiện không kiểm soát mức độ trung bình) và 1520(đại tiện không kiểm soát hoàn toàn). Đánh giá mức độ rối loạn đại tiện sau phẫu thuật tại các thời điểm 3 tháng- 6 tháng -12 tháng.

Xử lý số liệu: Kết quả nghiên cứu được xử lý bằng phần mềm thống kê y học SPSS 23.0. Các biến được biểu diễn dưới dạng trung bình, tỷ lệ \%. Kiểm định Chi bình phương, Fisher's test cho biến phân loại. Mức ý nghĩa thống kê với $p<0,05$.

\section{KẾT QUẢ NGHIÊN CỨU}

Từ tháng 7/2018 đến tháng 7/2020 có 82 BN được đưa vào nghiên cứu:

\section{Bảng 1. Đăc điểm bênh nhân}

\begin{tabular}{|c|c|}
\hline Đặc điểm bệnh nhân & $\begin{array}{c}\text { Số lượng, tỷ lệ } \\
\text { (n=82) }\end{array}$ \\
\hline Tuối (trung bình) & $62,8 \pm 11,6(28-84)$ \\
\hline Giới (nam/nữ) & $54 / 28$ \\
\hline \multicolumn{2}{|c|}{ Vị trí u, n (\%) } \\
\hline 1/3 trên & $23(28,0)$ \\
\hline 1/3 giữa & $41(50,0)$ \\
\hline 1/3 dưới & $18(22,0)$ \\
\hline Mức độ xâm lấn, n (\%) \\
\hline pT0 & $10(12,2)$ \\
pT1 & $4(4,9)$ \\
pT2 & $22(26,8)$ \\
pT3 & $39(47,6)$ \\
pT4 & $7(8,5)$ \\
\hline Di căn hạch, n (\%) \\
\hline N0 & $56(68,3)$ \\
N1 & $19(23,2)$ \\
N2 & $7(8,5)$ \\
N3 & $0(0)$ \\
\hline \multicolumn{2}{|c|}{} \\
\hline
\end{tabular}

Bảng 2. Đánh giá chức năng đại tiện sau phẫu thuật

\begin{tabular}{|c|c|c|c|}
\hline \multirow{2}{*}{ Điểm Wexner (trung bình) } & \multicolumn{3}{|c|}{ Thời gian theo dõi } \\
\cline { 2 - 3 } & $\mathbf{3}$ tháng & $\mathbf{6}$ tháng & $\mathbf{1 2}$ tháng \\
\hline Bình thường, \%(n) & 5,9 & 4,6 & 3,4 \\
\hline Rối loạn mức đô nhẹ, \%(n) & $28,0(23)$ & $34,1(28)$ & $46,3(38)$ \\
\hline Rối loạn mức độ trung bình \%(n) & $43,9(36)$ & $46,3(38)$ & $40,2(33)$ \\
\hline Mất kiếm soát hoàn toàn, \%(n) & $17,1(14)$ & $9,8(8)$ & $6,1(5)$ \\
\hline Điếm LARS (trung bình) & $11(9)$ & $9,8(8)$ & $7,3(6)$ \\
\hline Không có hội chứng LARS, \%(n) & 17,6 & 14,0 & 10,6 \\
\hline LARS mức độ nhẹ, \%(n) & $56,1(46)$ & $64,6(53)$ & $75,6(62)$ \\
\hline LARS mức độ nặng, \%(n) & $17,1(14)$ & $17,1(14)$ & $9,8(8)$ \\
\hline
\end{tabular}

LARS: Lower anterior resection syndrome (hội chứng cắt trước thấp)

Qua theo dõi chức năng đại tiện sau mổ ở thời điểm 3 tháng, 6 tháng và 1 năm thấy; sau 3 tháng điểm LARS trung bình là 17,6 (56,1\% không có LARS, $17,1 \%$ LARS nhe và $26,8 \%$ LARS nặng), sau 6 tháng lần lượt là $14,0(64,6 \%$, $17,1 \%$ và $18,3 \%$ ) và sau 12 tháng là 10,6 $(75,6 \%, 9,8 \%$ và $14,6 \%)$.

Thang điểm Wexner sau 3 tháng, điểm Wexner trung bình là 5,9 (28,0\% bình thường, 43,9\% rối loạn đại tiện mức độ nhẹ, $17,1 \%$ là rối loạn mức độ trung bình, $11,0 \%$ mất kiểm soát hoàn toàn), sau 6 tháng lần lượt là 4,6
$(34,1 \%, 46,3 \%, 9,8 \%$ và $9,8 \%)$, sau 12 tháng là $3,4(46,3 \%, 40,2 \%, 6,1 \%$ và $7,3 \%)$. Qua phân tích từ bàng 2 thấy rằng chức năng đại tiện được cải thiện đáng kể sau 12 tháng phẩu thuật.

Bảng 3. Các yêu tố liên quan đến hội chứng LARS mức độ năng

\begin{tabular}{|c|c|c|c|c|}
\hline \multicolumn{2}{|c|}{} & \multicolumn{2}{|c|}{ LARS nặng } & \multirow{2}{*}{ p } \\
\cline { 2 - 4 } \multicolumn{2}{|c|}{ Không } & Có & \\
\hline \multicolumn{3}{|c|}{ Tuối (n) } & & 0,092 \\
\hline & $\leq 60$ & 25 & 1 & \\
\hline & $>60$ & 45 & 11 & \\
\hline \multicolumn{2}{|c|}{ Nam/ Nữ } & $44 / 26$ & $10 / 2$ & 0,205 \\
\hline
\end{tabular}




\begin{tabular}{|c|c|c|c|}
\hline \multicolumn{3}{|c|}{ ASA (n, \%) } & 1,000 \\
\hline $\mathrm{I}$ & 49 & 8 & \\
\hline II & 21 & 4 & \\
\hline \multicolumn{3}{|c|}{ Hóa xạ tîên phâu (n) } & 0,017 \\
\hline Không & 23 & 0 & \\
\hline Có & 47 & 12 & \\
\hline \multicolumn{3}{|c|}{ Vị trí u (n) } & 0,020 \\
\hline 1/3 Trên & 23 & 0 & \\
\hline 1/3 Giữa & 34 & 7 & \\
\hline 1/3 Dưới & 13 & 5 & \\
\hline \multicolumn{3}{|c|}{ Phương pháp thực hiện miệng nối (n) } & 0,01 \\
\hline Nối máy & 56 & 5 & \\
\hline Nối tay & 14 & 7 & \\
\hline \multicolumn{3}{|c|}{ Vị trí miệng nối } & 0,000 \\
\hline Trên đường lượd & 52 & 3 & \\
\hline Tại đường lược & 14 & 4 & \\
\hline Dưới đường lượ & 4 & 5 & \\
\hline \multicolumn{3}{|c|}{ Dấn lưu hôi tràng (n) } & 0,320 \\
\hline Có & 25 & 2 & \\
\hline Không & 45 & 10 & \\
\hline \multicolumn{3}{|c|}{ Mức độ xâm lấn u trên GPB (n) } & 0,960 \\
\hline pT0 & 8 & 2 & \\
\hline pT1 & 4 & 0 & \\
\hline pT2 & 19 & 3 & \\
\hline pT3 & 33 & 6 & \\
\hline pT4 & 6 & 1 & \\
\hline
\end{tabular}

LARS: Lower anterior resection syndrome (hội chứng cắt trước thấp)

Kiểm định theo phương pháp Fisher's test

Phân tích đơn biến cho thấy; hóa xạ trị tiên phẫu $(p=0,017)$, vị trí khối $u(p=0,02)$ và phương pháp thực hiện miệng nối $(p=0,01)$, vị trí miệng nối $(p=0,000)$ có liên quan đến mức độ LARS nặng sau phấu thuật (bảng 3).

\section{BÀN LUÂN}

Rối loạn chức năng đại tiện của bệnh nhân sau phẫu thuật cắt trực tràng là vấn đề thách thức ảnh hướng nhiều đến chất lượng sống bệnh nhân sau phẫu thuật [2]. Hội chứng LARS được cho là do 3 nguyên nhân; thứ nhất, rối loạn nhu động của đại tràng, nghiên cứu cho thấy rằng tăng nhu động của đại tràng trái sau khi cắt sigma- trực tràng. Thứ hai, rối loạn chức năng chứa của trực tràng mới. Thứ ba, là do rối loạn chức năng cơ thắt hậu môn sau phẫu thuật. Có nhiều công cụ để đánh giá chức năng đại tiện được đưa ra để đánh giá chức năng đại tiện của bệnh nhân sau phẫu thuật. Tuy nhiên, nhiêu nghiên cứu cho thấy rằng việc phối hợp thang điểm LARS và Wexner là một đánh giá tốt cho vấn đề này [3], [2].

Trong nghiên cứu thấy rằng điểm mức độ rối loạn đại tiện thay đổi rõ rệt sau 1 năm điểm trung bình LARS sau 3 tháng, 6 tháng và 12 tháng lần lượt là 17,$6 ; 14,0$ và 10,6 . Trong đó, tại thời điểm 3 tháng sau phẫu thuật có $56,1 \%$ bệnh nhân không có LARS, tăng lên 75,6\% sau 12 tháng. Tỷ lệ bệnh nhân LARS nặng sau 3 tháng $26,8 \%$ giảm còn $14,6 \%$ sau 12 tháng.

Đánh giá bằng thang điểm Wexner: sau 3 tháng điểm Wexner trung bình là 5,9 giảm còn 3,4 sau 12 tháng. Tỷ lệ bệnh nhân đại tiện bình thường sau 3 tháng $28,0 \%$ tăng lên $46,3 \%$ sau 12 tháng. Sau 3 tháng có $11,0 \%$ bệnh nhân mất tự chủ hoàn toàn giảm còn $7,3 \%$ sau 12 tháng (Bảng 2). Nghiên cứu của Chen và cộng sự cho thấy tỷ lệ LARS nặng 46\% tất cả các bệnh nhân (56\% hóa xa trị kết hợp với TME, 35\% TME) theo dõi sau 14,6 năm với độ tuổi trung bình là 75 tuổi [8]

Theo Dulskas và cộng sự cho thấy 46,4\% (58/125) bệnh nhân có hội chứng LARS trong đó $26,4 \%$ LARS nhe và $20 \%$ LARS nặng. Điểm Wexner; bình thường 34,4\%, đại tiện không tự chủ mức độ nhẹ 44\%, mức độ trung bình 14,4\% và đại tiện mất tự chủ hoàn toàn là $7,2 \%$ với thời gian theo dõi trung bình 7,5 năm [3]. Ngoài ra, trong một nghiên cứu của Ekkarat và cộng sự nghiên cứu trên 129 bệnh nhân (67 nam và 62 nữ) thấy $65,2 \%$ (84/129) không có hội chứng LARS và $17,8 \%(23 / 129)$ có hội chứng LARS nhẹ, chỉ 17,8\% (23/129) có hội chứng LARS nặng [4]. Tương tự, Miacc và cộng sự nghiên cứu cho thây trên 64 bệnh nhân với độ tuổi trung bình $60,1 \pm 11,4$ có $67,7 \%$ (42/64) bênh nhân không có hội chứng LARS, 32,3 \% bệnh nhân có hội chứng LARS [7]. Trong nghiên cứu của chúng tôi đánh giá sau 12 tháng gặp 14,6\% bênh nhân có hội chứng LARS năng, găp nhiều ở nhóm ung thư trực tràng giữa và dưới (có 12/59 bệnh nhân ở nhóm trực tràng giữa - dưới).

Các nghiên cứu cũ̃ng chỉ ra rằng yếu tố về tuổi, điều trị hóa xa bổ trơ, khoảng cách miênng nối, vị trí khối u là những yếu tố liên quan đến hội chứng LARS nặng sau phẫu thuật [3], [7], [6]. Nghiên cứu của Liu và cộng sự thấy rằng các yếu tố liên quan đến hội chứng LARS nặng: tiền sử hóa xạ trị $(R R=5.608,95 \% C I: 1.457$ - 21.584, $\mathrm{P}=0.006)$, khoảng cách u đến mép hậu môn ( $R R=0.125$, 95\%CI:0.042 to 0.372, $\mathrm{P}=0.000$ ), khoảng cách miệng nối đến mép hậu môn $(R R=0.255,95 \% C I: 0.098$ to $0.665, P=0.004)$ và mở hồi tràng bảo vệ ( $R R=3.643,95 \% C I: 1.058$ to 12.548, $\mathrm{P}=0.032$ ) [6]. Tương tự, nghiên cứu của Miacc và cộng sự cho thây các yếu tố như điều trị tân bổ trợ $(p=0,0014)$, khoảng cách miệng nối đến mép hậu môn $(p<0,001)$, vị trí khối u và 
dẫn lưu hồi tràng là những yếu tố liên quan đến hội chứng LARS nặng sau phẫu thuật [7].

Trong nghiên cứu, phân tích các yếu tố liên quan bằng phương pháp Fisher's test cho thây; tại thời điểm 12 tháng sau phẫu thuật, các yếu tố điều trị hóa xạ trước mổ, vị trí u, vị trí miệng nối (trên đường lược, tại đường lược, dưới đường lược) và phương pháp thực hiện miệng nối có liên quan đến hội chứng LARS nặng sau mổ với $\mathrm{p}<0,05$ (bảng 3). Các nghiên cứu cho thấy rằng: đối với những tổn thương ung thư trực tràng thấp đồng nghĩa với thực hiện miệng nối thấp thì phẫu thuật là tăng nguy cơ tổn thương thần kinh tự động và cơ thắt hậu môn. Ngoài ra thể tích chứa phân của trực tràng mới giảm dẫn đến tăng nhu động ruột và đại tiện gấp[3], [2]. Đặc biệt những tổn thương ung thư trực tràng thấp $(<5 \mathrm{~cm})$ phần lớn bệnh nhân được thực hiện cắt trực tràng gian cớ thắt (có thể cắt bán phần, gần hoàn toàn và hoàn toàn cơ thắt trong) với miệng nối đại tràng ống hậu môn điều này có ảnh hưởng nhiều đến chức năng đai tiện của bệnh nhân sau phẫu thuật. Do vậy phẩu thuật viên cần tôn trọng cấu trúc giải phẫu, tránh tổn thương thần kinh tự động và bảo tồn tối đa cơ thắt hậu môn.

Nghiên cứu của chúng tối có một số hạn chế: việc đánh giá chức năng đại tiện sau phẫu thuật chỉ dựa vào các thang điểm đánh giá mà chưa có đánh giá bằng phương tiện đo áp lực hậu môn trực tràng. Ngoài ra, cần nghiên cứu trên số liệu bểnh nhân lớn hơn và thời gian theo dõi xa hớn để có đánh giá toàn diện hơn.

\section{KẾT LUẦN}

Rối loạn chức năng đại tiện của bệnh nhân ung thư trực tràng được phẫu thuật cắt trước thấp là vấn đề thường gặp và kéo dài sau phẫu thuật, chức năng đại tiện sẽ được phục hồi dần theo thời gian. Do đó theo dõi, hỗ trợ, tư vấn và điều trị của bác sĩ có ý nghĩa trong việc cải thiện chất lượng sống tốt hơn cho người bệnh.

\section{TÀI LIÊU THAM KHẢO}

1. Beppu N., et al., "Long-Term Functional Outcomes of Total Mesorectal Excision Following Chemoradiotherapy for Lower Rectal Cancer: Stapled Anastomosis versus Intersphincteric Resection", Dig Surg. 2016. 33, pp. 33-42.

2. Chen T.Y.T., Emmertsen K.J., Laurberg S., "What Are the Best Questionnaires To Capture Anorectal Function After Surgery in Rectal Cancer?", Curr Colorectal Cancer Rep. 2015. 11, pp. 37-43.

3. Dulskas A., et al., "Long-term bowel dysfunction following low anterior resection", Sci Rep. 2020. 10: 11882.

4. Ekkarat $\mathbf{P}_{\text {., }}$ et al., "Factors determining low anterior resection syndrome after rectal cance resection: A study in Thai patients", Asian J Surg. 2016. 39, pp. 225-231.

5. Emmertsen K.J., Laurberg S., "Low anterior resection syndrome score: development and validation of a symptom-based scoring system for bowel dysfunction after low anterior resection for rectal cancer", Ann Surg. 2012. 255, pp. 922-928.

6. Liu F., et al., "Risk factor analysis of low anterior resection syndrome after anal sphincter preserving surgery for rectal carcinoma", Chin J Gastrointest Surg. 2017. 20, pp. 289-294.

7. Miacci F.L.C., Guetter C.R., et al, "Predictive factors of low anterior resection syndrome following anterior resection of the rectum", Rev Col Bras Cir. 2020. 46:e20192361.

8. T.Y.T. Chen, L.M. Wiltink, "Bowel function 14 years after preoperative short-course radiotherapy and total mesorectal excision for rectal cancer: report of a multicenter randomized trial", Clin Colorectal Cancer. 2015. 14, pp. 106-114.

\title{
NGHIÊN CỨU CHỨC NĂNG THẤT PHẢI TRÊN SIÊU ÂM TIM Ở BỆNH NHÂN HẸP VAN ĐộNG MACH CHỦ KHÍT
}

\author{
Đỗ Mạnh Hùng ${ }^{1}$, Nguyễn Thị Hải Yến ${ }^{2}$, Nguyễn Thị Bạch Yến ${ }^{2}$
}

\section{TÓM TẮT}

Mục tiêu: Tìm hiểu tỷ lệ suy CN thất phải và mối liên quan giữa chức năng thất phải với một số thông

\footnotetext{
${ }^{1}$ Bệnh viện Bãi Cháy

${ }^{2}$ Bệnh viện Bach Mai

Chị trách nhiệm chính: Đỗ Manh Hùng

Email: manhhung180689@gmail.com

Ngày nhận bài: 13.9.2021

Ngày phản biên khoa họ: 29.10.2021

Ngày duyệt bài: 15.11.2021
}

số đánh giá mức độ hẹp van động mạch chủ và chức năng thất trái trên siêu âm tim ở nhóm bệnh nhân hẹp van động mạch chủ khít. Đối tượng: $B N$ hẹp van ĐMC khít (theo tiêu chuẩn của hôi siêu âm tim hoa kì: vận tốc tối đa qua van $>4 \mathrm{~m} / \mathrm{s}$, diện tích mở van động mach chủ $<1 \mathrm{~cm} 2$, chênh áp trung bình qua van $>40$ $\mathrm{mmHg}$ ) đến khám và điều trị tại Viện tim mạch từ tháng 8/2020-8/2021.Phương pháp nghiên cứu: mô tả cắt ngang chùm ca bệnh. Chọn mẩu thuận tiện. Siêu âm tim đánh giá $\mathrm{CN}$ thất phải (TAPSE, FAC, 'S', E/e' thành bên van ba lá, chỉ số Tei mô thất phải, ĐK thất phải). Kết quả: $47 \mathrm{BN}$ hẹp chủ khít đã được nghiên cứu siêu âm tim. Tỷ lệ suy chức năng thất phải 